\title{
Exergy analysis of the multi-stage slag waste heat recovery system
}

\author{
Wenjun Duan ${ }^{1, *}$, Xiaojun $\mathrm{Lv}^{1}$, Zhimei Wang ${ }^{2}$, and Dan Zhao ${ }^{2}$ \\ ${ }^{1}$ School of Metallurgy, Northeastern University, Shenyang 110819, Liaoning, China \\ ${ }^{2}$ Shenyang Metrology Testing Institution, Shenyang 110179, Liaoning, China
}

\begin{abstract}
Based on the black-box model, this paper analyzed the multi-stage slag waste heat recovery system. The exergy efficiency, the exergy loss coefficient and the exergy loss rate were adopted as evaluation indexes to investigate the energy consumption and the weakness of the system. Meanwhile, the performance of waste heat recovery was analyzed by comparing the comprehensive exergy efficiency between the system and other conventional waste heat recovery methods. The results showed that the comprehensive exergy efficiency of the system reached $75.75 \%$, which was much higher than other methods, and the weakness of the system was the subsystem of waste heat boiler. In general, the system recovered the slag waste heat effectively and converted coal to clean syngas through gasification reaction, which had incredible potential in energy saving, emission reduction and consumption reduction.
\end{abstract}

\section{Introduction}

Iron and steel industry was the basic industry of a country and also an energy-intensive industry, which accounted for $4-5 \%$ of the total world energy consumption [1, 2]. As a kind of by-product, blast furnace slag was discharged at $1773-1873 \mathrm{~K}$ and carried amount of energy of about $1700 \mathrm{MJ} / \mathrm{t}_{\text {slag }}$ [3]. Therefore, the waste heat recovery from slag was a key point to achieve the object of energy saving and emission reduction for iron and steel industry.

At present, the main method of slag waste heat recovery was physical method. However, physical method wasted large amounts of high-quality sensible heat and had low efficiency of waste heat recovery. With the study development of the slag waste heat recovery, some researchers proposed chemical method to recover the waste heat. Chemical method of waste heat recovery from slag referred to the fundamental change of chemical properties in the process of heat release from slag or the chemical change of other substances involved in the process of waste heat recovery. Kasai et al. [4] proposed the method of methane steam reforming process using slag waste heat. Maruoka [5] found that $51 \%$ of slag waste heat could be recovered through methane steam reforming reaction, and $299 \mathrm{~kg}$ of slag could produce about $106 \mathrm{Nm}^{3}$ combustible gas. Takayasu [6] studied the kinetics of methane carbon dioxide reforming reaction to recover the waste heat from slag and the methane conversion rate reached a maximum of $96 \%$. Zhao [7] studied gas production of combustible gas production from municipal solid waste using slag as heat carrier. It was found that the volume fraction of syngas of using different gasification agent decreased in the order steam $>$ air $>\mathrm{N}_{2}$. Liu [8] proposed a concept of coal gasification reaction to produce syngas using furnace slag as heat carrier. Luo et al. [9] proposed an experimental system for the production of hydrogenrich syngas by biomass gasification using slag waste heat. Sun et al. [10] also studied the low-temperature gasification reaction of biomass catalyzed by slag as heat carrier. The research of coal gasification using slag to produce the syngas was carried out by $\mathrm{Li}$ [11]. Duan et al. [12] conducted a series of studies on steam gasification combining with slag waste heat recovery.

In this paper, the exergy analysis was carried out on the multi-stage slag waste heat recovery system, the exergy input and output of each subsystem were calculated, and the comprehensive exergy efficiency was used as the index to compare the system with other waste heat recovery methods, thereby the performance of the system's waste heat recovery was effectively evaluated.

\section{Theoretical analysis}

\subsection{System selection}

In this paper, the multi-stage slag waste heat recovery system was selected as analytic target [13]. The system was generally composed of three subsystems: molten slag gasifier, solid granules slag gasifier and waste heat boiler. The analysis of the system was conducted which based on the exergy analysis method and the black-box model.

\subsection{Exergy theory}

*Corresponding author: duanwenjn@163.com 


\subsubsection{Physical exergy}

(1) Enthalpy exergy

The enthalpy exergy was expressed by $E_{x, H}$, and the equation was as follows:

$$
E_{x, H}=\int_{T}^{T_{0}} m c_{p}\left(1-\frac{T_{0}}{T}\right) d T
$$

where, $c_{p}$ was the heat capacity at constant pressure; $T$ was the system temperature, $\mathrm{K} ; T_{0}$ was the environment temperature, $\mathrm{K}$.

(2) Heat exergy

Under the given environmental conditions, the maximum available work obtained by the energy transmitted by the system in reversible method was called heat exergy, which was expressed by $E_{X, Q}$, and the equation was as follows:

$$
E_{X, Q}=\int_{1}^{2}\left(1-\frac{T_{0}}{T}\right) \delta Q
$$

\subsubsection{Chemical exergy}

Fuel exergy was defined as the maximum useful work that could be done to reversibly change to a completely balanced environmental state when the fuel and oxygen stably entered into the chemical reaction system under a benchmark environment of a certain $T_{0}$ and $P_{0}$. The equations were as follows:

The exergy of gas fuel: $\quad E_{X, f}=0.95 Q_{H}$

The exergy of liquid fuel: $\quad E_{X, f}=0.975 Q_{H}$

The exergy of solid fuel: $\quad E_{X, f}=Q_{L}+r \omega$

where, $Q_{L}$ was the fuel lower heating value, $\mathrm{kJ} / \mathrm{kg}$; $Q_{H}$ was the fuel higher heating value, $\mathrm{kJ} / \mathrm{kg} ; r$ was the latent heat of vaporization, $\mathrm{kJ} / \mathrm{kg}$; $\omega$ was the mass percentage of water in fuel, $\%$.

\subsection{Model description}

In this paper, the exergy input included the supply exergy and the bring exergy, while the exergy output included effective exergy and ineffective exergy, and the internal loss was caused by irreversibility. The models of each subsystem were shown in Fig. 1.

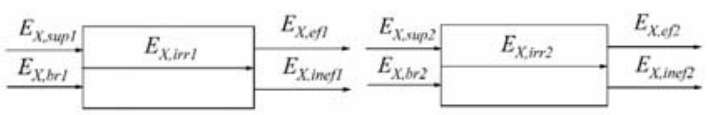

(a)

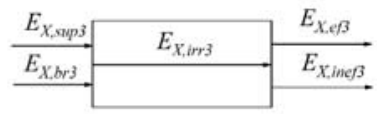

(c)

Fig. 1. The black-box model:(a) molten slag gasifier;(b) solid granules slag gasifier;(c) waste heat boiler.

\subsection{Results of exergy input and output}

In order to better understand the energy usage of the system, the exergy input and output of each subsystem were calculated.

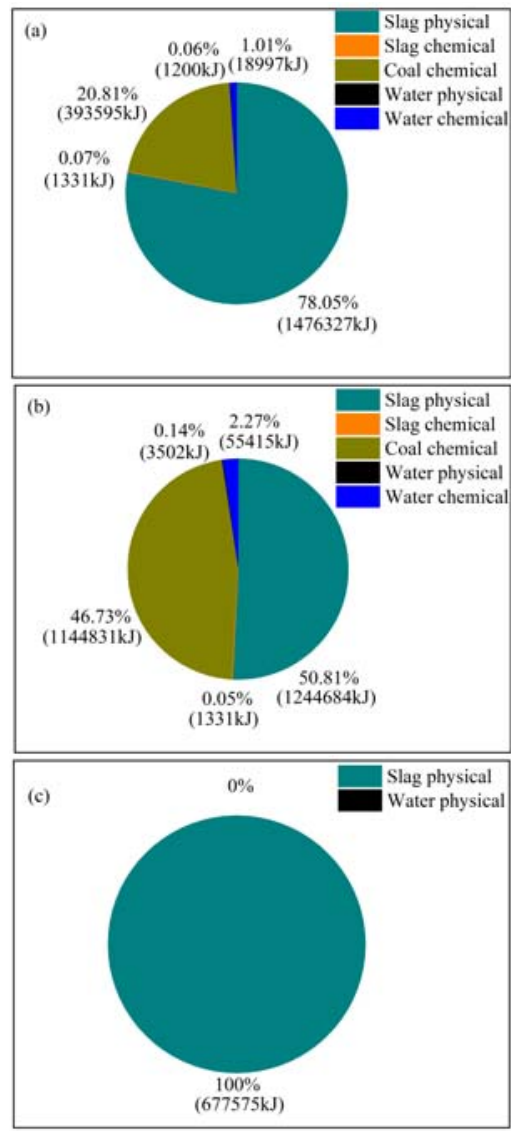

Fig. 2. Exergy input distribution:(a) molten slag gasifier;(b) solid granules slag gasifier; (c) waste heat boiler.

Fig. 2 and Fig. 3 showed the distribution of exergy input and output of each subsystem. As could be seen from Fig. 2, in the molten slag gasifier, the slag physical exergy accounted for $78.05 \%$ of the total exergy input, the second was the coal chemical exergy with $20.81 \%$. The majority of exergy input of solid granules slag gasifier were the slag physical exergy and the coal chemical exergy, the slag physical exergy accounted for $50.81 \%$ and the coal chemical exergy accounted for $46.73 \%$. The exergy input of waste heat boiler was a single one consisting solely of the slag physical exergy. As could be seen from Fig. 3, in the molten slag gasifier, the slag physical exergy accounted for $65.81 \%$ of the total exergy output, the second was the syngas chemical exergy with $27.09 \%$. In the solid granules slag gasifier, the syngas chemical exergy accounted for $60.75 \%$ of the total exergy output, the second was the slag physical exergy with $27.66 \%$. The exergy output of waste heat boiler was approximately trisected by the slag physical exergy, the steam physical exergy and the internal exergy loss.

\section{Results and discussion}




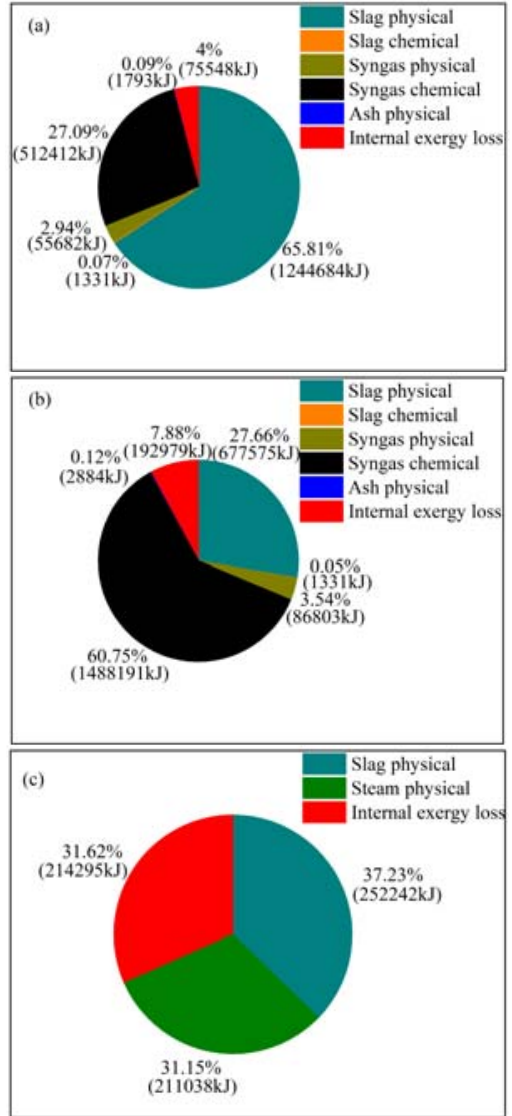

Fig. 3. Exergy output distribution:(a) molten slag gasifier;(b) solid granules slag gasifier;(c) waste heat boiler.

\subsection{Analysis of exergy evaluation index}

As could be seen from Fig. 4, the exergy efficiency of solid granules slag gasifier was the highest among three subsystems, which reached $64.29 \%$. The reason was that the exergy efficiency was related to the temperature range of the slag in subsystems. In addition, the performance of chemical waste heat recovery was better than that of physical waste heat recovery. In terms of the internal exergy loss rate, that of waste heat boiler was the highest with $45.93 \%$. This could be explained that the subsystem was too irreversible to output the effective exergy. Therefore, waste heat boiler was the weakness of the whole system due to its large internal exergy loss and low exergy efficiency. As for the problem of low exergy efficiency of waste heat boiler system, it could be tried to further reduce the discharge temperature of the slag. As shown in Fig. 5, the comprehensive exergy efficiency of the whole system was $75.75 \%$, which indicated that the system recovered the slag waste heat efficiently.

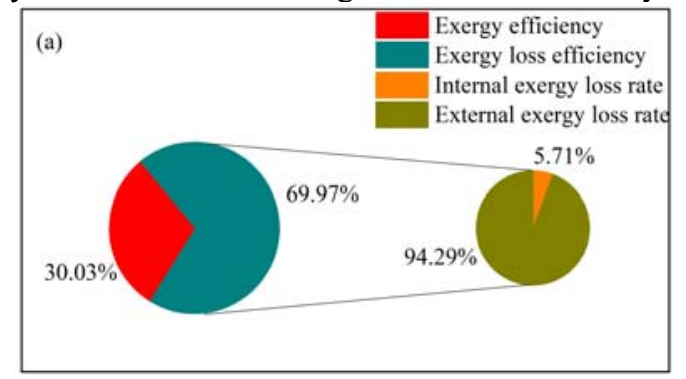

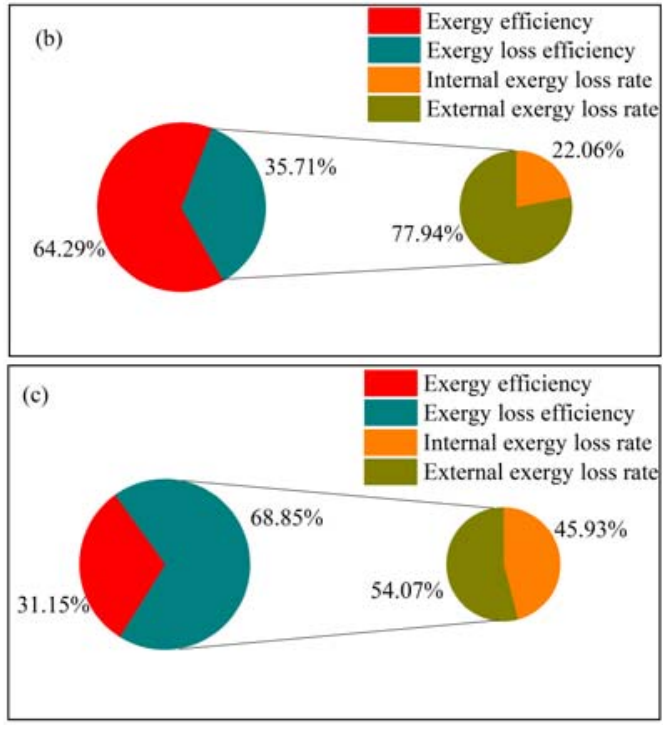

Fig. 4. The evaluation indexes of subsystems:(a) molten slag gasifier;(b) solid granules slag gasifier;(c) waste heat boiler.

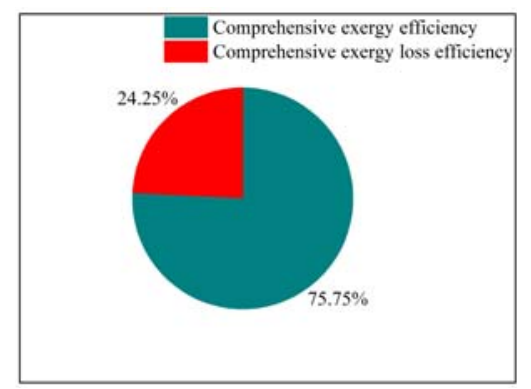

Fig. 5. The evaluation indexes of the multi-stage slag waste heat recovery system.

\subsection{Comparison of different methods}

In order to study the energy utilization of the slag waste heat recovery system, the comprehensive exergy efficiency of the system granulated by solid slag impingement, the system granulated by air blasts, and the system using water quenching method were also calculated. These results were shown in Fig. 6.

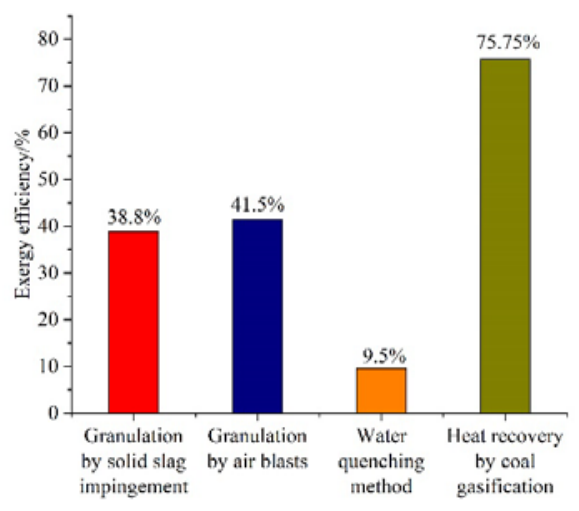

Fig. 6. The comprehensive exergy efficiency comparison of different methods.

Fig. 6 showed that the comprehensive exergy efficiency of the system granulated by solid slag impingement reached $38.8 \%$ and that of the system 
granulated by air blasts reached $41.5 \%$. The system using water quenching method had the lowest comprehensive exergy efficiency with $9.5 \%$. However, the comprehensive exergy efficiency of coal gasification waste heat recovery system reached $75.75 \%$, which was obviously superior to the other methods in utilizing energy and improving energy quality. By comparison, the comprehensive exergy efficiency of the system was $36.95 \%$ higher than that of the system granulated by solid slag impingement, $34.25 \%$ higher than that of the system granulated by air blasts, and $66.25 \%$ higher than that of the system using water quenching method. It was because that the system adopted the multi-stage waste heat recovery with the coupling of physical method and chemical method. The slag waste heat was recovered through the molten slag gasifier at the first stage, then granulated by granulation device, and next entered into the solid granules slag gasifier at the second recovery stage, finally the waste heat boiler as the third stage produced steam to supply the power station. Meanwhile, the steam required in the whole process was selfsufficient. The results suggested that the coal gasification waste heat recovery system could effectively recover the waste heat resources of the slag, and had a broad application prospect for saving energy and reducing environmental pollution.

\section{Conclusions}

This work calculated the exergy input and output of each subsystem, and analyzed the energy consumption of each subsystem. Besides, the exergy efficiency, exergy loss coefficient and exergy loss rate were obtained, and the comprehensive exergy efficiency of the whole system was compared with other conventional waste heat recovery methods. The main conclusions were as follows:

(1). The waste heat boiler was the weakness of the system, its exergy loss coefficient reached $68.85 \%$, and the internal exergy loss rate of $45.93 \%$ was the highest of the three subsystems, it should be tried to reduce the internal irreversibility of waste heat boiler to reduce the internal exergy loss.

(2). The system adopted the multi-stage waste heat recovery and combined physical method and chemical method. And the comprehensive exergy efficiency of the multi-stage slag waste heat recovery system reached $65.73 \%$. In the process of comparing the system with the other systems, it was found that the comprehensive exergy efficiency of the system was higher than the other three systems. Therefore, the system had great energy saving potential in the application of blast furnace slag waste heat recovery.

\section{Acknowledgments}

This research was supposed by The National Natural Science Foundation of China (51704071), The Fundamental Research Funds for the Central Universities (N2025006).
1. GY. Ma, JJ. Cai, WW. Zeng, H. Dong Analytical research on waste heat recovery and utilization of China's iron \& steel industry Energy Procedia 14,1022-8(2012)

2. RB. Cahyono, AN. Rozhan, N. Yasuda, T. Nomura, Y. Kashiwaya, T. Akiyama Integrated coalpyrolysis tar reforming using steelmaking slag for carbon composite and hydrogen production Fuel 109,439-44(2013)

3. YQ. Sun, S. Seetharaman, QY. Liu, ZT. Zhang, LL. Liu, XD. Wang Integrated biomass gasification using the waste heat from hot slags: control of syngas and polluting gas releases Energy 114,16576(2016)

4. E. Kasai, T. Kitajima, T. Akiyama, J. Yagi, F. Saito Rate of methane-steam reforming molten BF slag for heat recovery a chemical reaction on from molten the surface of slag by using a chemical reaction ISIJ Int 37,1031-6(1997)

5. N. Maruoka, T. Mizuochi, H. Purwanto, T. Akiyama Feasibility study for recovering waste heat in the steelmaking industry using a chemical recuperator ISIJ Int 44,257-62(2004)

6. O. Takayasu, Y. Takegahara, I. Matsuura Thermogravimetric study in connection with the $\mathrm{CO}_{2}$-reforming reaction of $\mathrm{CH}_{4}$ Energy Convers Manage 36(6-9),597-600(1995)

7. LM. Zhao, H. Wang, S. Qing, HL. Liu Characteristics of gaseous product from municipal solid waste gasification with hot blast furnace slag $\mathrm{J}$ Nat Gas Chem 19,403-8(2012)

8. HX. Liu Investigation of coal gasification using blast furnace molten slag as heat carrier Energy Conserv 6,41-3(2004)

9. SY. Luo, YM. Zhou, CJ. Yi Hydrogen-rich gas production from biomass catalytic gasification using hot blast furnace slag as heat carrier and catalyst in moving bed reactor Int J Hydrogen Energy 37,15081-5(2012)

10. YQ. Sun, ZT. Zhang, S. Seetharaman, LL. Liu, XD. Wang Characteristics of low temperature biomass gasification and syngas release behavior using hot slag RSC ADV 4,62105-14(2014)

11. P. Li, W. Lei, B. Wu, QB. Yu $\mathrm{CO}_{2}$ gasification rate analysis of coal in molten blast furnace slag-For heat recovery from molten slag by using a chemical reaction Int J Hydrogen Energy 40,1607-15(2015)

12. WJ. Duan, QB. Yu, K. Wang, Q. Qin, LM. Hou, X. Yao, TW. Wu ASPEN Plus simulation of coal integrated gasification combined blast furnace slag waste heat recovery system Energy Convers Manage 100,30-6(2015)

13. WJ. Duan, QB. Yu, ZM. Wang, JX. Liu, Q. Qin Life cycle and economic assessment of multi-stage blast furnace slag waste heat recovery system Energy 142,486-95(2018)

\section{References}

